\title{
Australian pap Smear Registers and the Creation of GENDERED IDENTITIES
}

Joanne Stagg-Taylor ${ }^{*}$

\begin{abstract}
Governments in several Australian jurisdictions have enacted legislation that creates cervical cancer registers. Unlike other legislation relating to several other types of health register, cervical cancer register legislation sets up oversight, reminder and information-gathering regimes about all patients who undergo testing for cervical cancer. The government sets up reminder systems and information-gathering from which women must opt out rather than opting in to use the system. This article examines cervical cancer register legislation and compares and contrasts legislative regimes that address comparative health regimes. Using textual analysis and a feminist theoretical model, the article examines how women are treated differently from patient groups comprising mainly men or mixed-gender groups. It then analyses how the legislation creates and reinforces gender identities.
\end{abstract}

Science and medicine construct images and identities of doctors, scientists, patients and experimental subjects. ${ }^{1}$ Those discipline-based tropes become socially authoritative, informing legislation that in turn regulates medical activities. Together, law and medicine affect and effect social perceptions of the subjects and objects of law and medicine. This article will investigate one model of intertwined law, technology and medical practice - Pap smears and legislative registers of Pap smear test results - to examine how they reinforce and recreate social norms and gendered identities.

Australia has a national system of cervical cancer screening, based on population testing and Pap smear registers. Using the example of the Queensland Pap Smear Register and the Public Health Act 2005 (Qld), this article will examine how cervical cancer screening legislation is both informed by and reifies stereotypical gendered identities for women. The text of the Public Health Act 2005 (Qld) will be examined for its explicit and implicit othering of women, and the particularly gendered identities it assumes and creates. It will also consider whether such an approach is justified on utilitarian medical grounds.

The first section provides a short overview of the author's theoretical framework. This is followed by an overview of the legislative framework for the Queensland Pap Smear Register. The following section analyses how the Pap smear register legislation adopts and reinforces gendered identities,

Lecturer, Griffith Law School.

Fujimura (1996), p 19 
concluding that there are significant and damaging gender stereotypes underlying the Pap Smear Register legislation. The article then goes on to consider whether the benefits of the legislation justify harmful stereotyping and reductions in rights by comparing historical and international cervical screening outcomes and approaches. Finally, it concludes with a summary of the gendered identities created and reinforced by the Pap Smear Register provisions of the Public Health Act 2005 (Qld).

\section{Gender, identity, medicine and discipline}

This article argues that the Queensland Public Health Act creates gendered identities. But what is meant by 'gendered identity'? How can legislation create gendered identities? Kendall and Michael explain that the term identity is used frequently ... to refer to some sense of self, and especially to a self-reflective sense of self' ${ }^{2}$ Latour would expand the idea of identity to include qualities imposed upon a person by external actors/technologies, which may or may not be internalised, but which will affect how others perceive the person. ${ }^{3}$ Kendall and Michael argue that 'humans ... are always relational, always between networks' ${ }^{4}$ and that these relational networks act to create social and self-perceptions. Foucault ${ }^{5}$ states that, in his view, the self is not a reality to be discovered but rather a product of the technologies of the self in our culture. He further theorises that those technologies of the self are spread across medicine, education, disciplinary power and psychoanalysis. ${ }^{6}$ Sociologists consider that identity is an artefact of cognitive schemas reinforced by both internal conceptions of self and the social reinforcement of roles and identities. ${ }^{7}$ Foucault's technologies of the self and Latour's network of influences are key to the creation of identity schemas and to their reinforcement.

Howard explains sociological conceptions of the formation of gender identities as follows:

gender identities, in the sense of organizing a sense of self around the perception one is female or male, and internalizing pre- and proscriptions of behaviours deemed culturally appropriate to these self perceptions, are thought to be learned through early socialization and enacted and reinforced throughout the lifespan. ${ }^{8}$

Gender is fundamental to social construction of identity. ${ }^{9}$ Following West and Zimmerman's conception of gender as a performative expression of sex

Kendall and Michael (nd), 3.32

Kendall and Michael (nd), discussing Bruno Latour (1993) We Have Never Been Modern Harvester Wheatsheaf

Kendall and Michael (nd)

Foucault (1983).

Foucault (1983).

Howard (2000); Howard (2000).

Howard (2000).

Ridgeway (2009). 
categorisation, ${ }^{10}$ one could, in a simplistic approach based on their theory, reject gendered roles, stereotypes and performances. However, gender is not a costume that one adopts with ease and puts aside. Gender entails both external and internal perceptions of identity below and beyond one's control. One has sex (based on biological markers), sex categorisation ('established and sustained by the socially required identification displays that proclaim one's membership in one or the other category' in normative binary categories of male or female) and gender ('the activity of managing situated conduct in light of normative conceptions of attitudes and activities appropriate for one's sex category'). ${ }^{11}$ There are penalties for failing to perform gender or for performing it incorrectly. ${ }^{12}$

Gender is more than a mere performance, being rather 'a powerful ideological device, which produces, reproduces and legitimates the choices and limits that are predicated on sex category'. ${ }^{13}$ Women's perception of the need to comply with gender roles is 'both internalised and externally imposed' ${ }^{14}$ West and Zimmerman propose that all gender role and identity compliance or rejection is subject to 'gender assessment', which creates gender accountability and enforcement across all social frameworks. ${ }^{15}$ The regulation of gender is both the 'institutionalization of the process by which persons are made regular' ${ }^{16}$ and, as the product of a distinctive regulatory and disciplinary regime' that is itself gendered,${ }^{17}$ the result of an intensive normative process that is 'invoked and cited by bodily practices that also have the capacity to alter norms in the course of their citations'. ${ }^{18}$ There are social punishments and repercussions for those who fall outside or challenge gender norms. ${ }^{19}$ Constant social surveillance and awareness of social disciplinary power lead to internalisation of gender norms ${ }^{20}$ and values, which then become integral to individual identities and perceptions of the gendered self.

How, then, is gender identity constructed in Australian law? Naffine has summarised the liberal ideal citizen, who was specifically gendered as male, as, 'Ideal male citizens ... rational, independent, self-directed, autonomous and cultural, in dramatic contrast to the dependent, emotional, natural, passive female. ${ }^{21}$ The liberal individual is generally a cis-gendered,

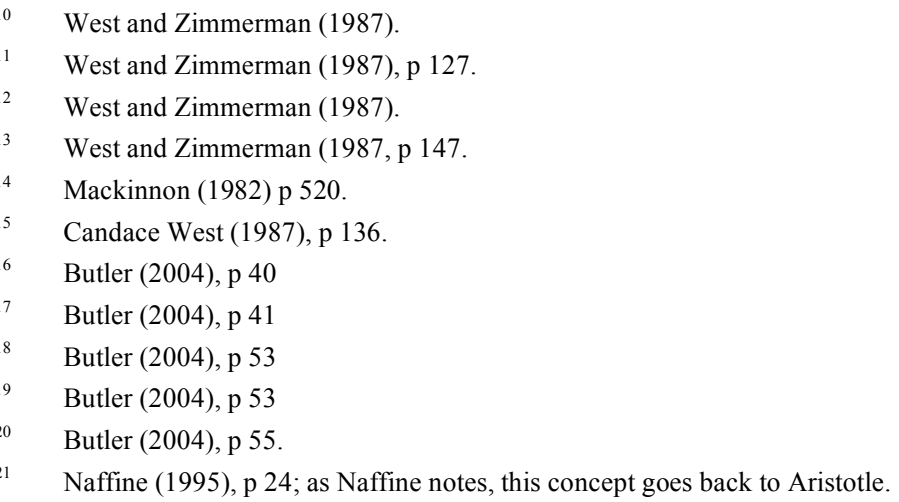


able-bodied, white man, who provides the norm of comparison against whom others are measured. ${ }^{22}$ In a presumed gender binary, women ${ }^{23}$ stand in contradistinction to men, ${ }^{24}$ the defining lesser, passive, irrational shade-relief to the light of rational modernity, a collection of vice-qualities that contrasted the active virtues of men: 'Man was the universal, the standard condition; woman was the particular case, the deviation from the standard. ${ }^{25}$ Where man was active, woman was passive; man rational, woman irrational; man autonomous, woman dependent; man objective and woman emotional (and therefore irrational, again).

This dichotomous stereotyping flowed into Australian law. In recent Australian legal history, as recently as the 1980 s, women were routinely required to supply a male guarantor for their loans, because they were presumed less than fully financially responsible. ${ }^{26}$ Similarly, the history of sexual consent law was influenced by centring the interests of men and the objectifying and stereotyping of women. In Australia, until the 1980s and 1990 s, rape in marriage was not possible, because the woman had given irrevocable consent to sex with marriage, ${ }^{27}$ submitting to a passive sexual role, devoid of sexual agency for the duration of the marriage. This recent historical presumption that women were irresponsible objects of men's rights underlies the evolution of Australian legal subjectification of men and objectification of women.

The law still denies full subjectivity to women. ${ }^{28}$ Where a woman reacts as a rational woman, rather than reflecting a male-normative standard, she is presumed to be irrational. For example, it is common and reasonable for women who fear escalated abuse to stay with their abuser, as they may fear attempts on their life or the lives of others if they attempt to end a relationship. Statistics show women are likely to face increased or deadly abuse when leaving an abusive relationship. ${ }^{29}$ Thus staying may in fact be the most rational option. The many women experiencing such a dilemma are treated as 'creatures of unreason', ${ }^{30}$ reflecting and reinforcing the traditional binary of rational men and irrational women.

Similarly, women are characterised by both the law and media as 'potential mothers of unborn children' ${ }^{31}$ a characterisation increasingly used as a justification and mechanism of control. ${ }^{32}$ Discourses of women in

Crenshaw (1996), p 172.

And others who are not gendered as cisgendered men.

Haraway (1991), p 210.

Naffine (1995), p 25.

Scutt (1997), p 224.

Scutt (1997), p 228.

Naffine (1995), p 20 and 21.

Mahoney et al (2001), p 163.

Naffine (1995), p 32.

Crenshaw (1996), p 173.

Scutt (1997), p 247. 
abortion law debates represent 'woman as a minor in terms of immaturity or underdevelopment with regard to matters of responsibility [and] morality'. ${ }^{33}$ 'The task for the law is thus perceived essentially as one of responsibilisation. ${ }^{, 34}$ After all, if men are responsible, women - as the binary opposite - must generally be irresponsible. The woman did not rationally and responsibly prevent a pregnancy, therefore, she must be irrational, and any decision to end a pregnancy must accordingly be irrational, irresponsible and a whim. To prevent a woman from making irrational mistakes about ending pregnancies, 'responsibility is handed over to the reassuringly mature and responsible (male) figure of the doctor' ${ }^{35}$ Such gender stereotyping shows 'the characteristic pattern of status inequality in which the higher status group is perceived as more proactive and agentically competent ... and the lower status group is seen as more reactive and emotionally expressive', as identified by Ridgeway. ${ }^{36}$

In addition, law and medicine often treat women as the object, rather than subject, of law and medical practice. ${ }^{37}$ In law, if men had rights to sex in marriage, the object of that right (women) had no right to complain of marital rape. ${ }^{38}$ Likewise, patients and test subjects become the objects of science and medicine. The doctor or scientist is the active subject of science while the patient has a passive role, being tested, waiting for results and following the (active and reasoned) recommendations of doctors and scientists. The subjectivity and agentic competence of the doctor is contrasted with a binary opposite of passivity and presumed ignorance on the part of the medical object - the patient - in roles that reflect traditional gender roles and the traditional gendering and status constructions of medical practice.

While the gender of doctors alters dynamics in patient care and communication, there are still status and role differentials that affect interaction between both male and female doctors and female patients tested under Australian cervical cytology testing regimes. Research on doctorpatient communication shows that female doctors, in conversation with female patients, still act out their higher status role. While showing highly encouraging communication styles with female patients, female doctors are also more likely to assume more stereotypically 'masculine' communication styles about medical content, heavy on medical jargon, when communicating with female patients rather than with male patients. ${ }^{39}$ It is likely that female doctors may foreground their institutional identity ${ }^{40}$ as a physician, rather

Sheldon (1993), p 20. Sheldon is referencing debates about UK abortion legislation.

Sheldon (1993), p 7.

Sheldon (1993), p 17.

Ridgeway (2009), p 149.

Naffine (1995), pp 27 and 35.

At least until the 1980s and 1990s in many Australian jurisdictions. Scutt (1997), p 228.

Sandhu et al (2009), p 351.

Ridgeway (2009), p 152. 
than their gender identity, when interacting with female patients, while still making unconscious gendered assumptions about female patients. At the same time, dyadic communication research shows that male doctors with female patients show the least patient-centred communication practices, discuss self-management of health significantly less than with male patients and stress screening processes more than in any other dyad of doctor-patient gender. ${ }^{41}$ Male doctors with male patients, by contrast, discuss patient selfcare and health-promotion activities in ways that also reflect greater presumptions of equality between doctor and patient, greater expectations of patient agency and with fewer communication strategies reflecting dominance behaviours by doctors. ${ }^{42}$

While some argue for a more feminist ethic of care as an approach to be centred in health and social care ethics and practice, ${ }^{43}$ especially by female practitioners, this borrows from somewhat essentialist approaches to gender that construct women as being gendered as care-centred, ${ }^{44}$ and does not affect gendered institutional approaches to female patients - particularly those of the type enacted in the Queensland Public Health Act's approach to cervical cytology screening. In focusing on the ethical orientation of individual doctors, it overlooks that gender identity creation is a 'multi-level system' that includes 'macro-structural/institutional levels', ${ }^{45}$ such as in a legislative milieu that institutionalises and reinforces gendered medical tropes. This article will examine how the Public Health Act 2005 (Qld) and cervical screening regime operate on gender norms at the macrostructural/institutional level, rather than the individual variations in care offered by doctors with differing orientations to ethics of care.

In addition to gender(ed) roles affecting medical transactions, medical research and technologies create their own new realities, by influencing what can be tested for, how testing is best done and how different health outcomes are interpreted. It resituates the role of doctors, patients, pathologists and others who interact with the technology, in a clear example of the interplay of human and the non-human discussed in actor network theory. ${ }^{46}$ Technologies include not only physical processes, like Pap smears themselves, but also record-keeping regimes, like the Pap Smear Register, as the record-keeping process does 'not merely represent but actively mediates the clinical encounter by directing the clinician's gaze' ${ }^{47}$ Thus doctors, and in turn their patients, are forced to reconsider and reconceptualise their roles with each change in medical technology, including legislatively mandated

\footnotetext{
$41 \quad$ Sandhu et al (2009), p 351.

42 Sandhu et al (2009), p 350.

43 Parton (2003); Sevenhuijsen (2003); Green (2012).

$44 \quad$ Mendus (1993).

$45 \quad$ Ridgeway (2009), p 146.

46 Timmermans and Berg (2003), esp p 104, where they say, 'The general purpose of this approach is to gauge what [medical] technologies do; what caring, curing or alternatives to those goals they help accomplish.' Fujimura (1996), p 19. 
record-keeping processes. In the face of medical technologies continually redefining medical roles, Timmerman and Berg consider that 'one can thus not presume a static immutable character such as gender or ethnicity but one should ask what kind of sexes are made and unmade in medicine' ${ }^{48}$ Medical technologies thus have a role to play in constructing and reproducing patient and professional identities, including gender identities. ${ }^{49}$

Cervical testing itself partakes of stereotyped gendered roles. The woman lies on her back, stationary, and is penetrated. The doctor is active, performing the test and penetrating the woman. The doctor's role reflects a heteronormative assumption of penetrators as active and rational, agentically competent, whatever the gender of the doctor, while the woman patient's role reflects patriarchal, heteronormative assumptions about women's role in heterosexual sex acts. The woman is passive, done-to, merely unresisting, not the active subject of the process. It becomes even easier to ascribe gendered assumptions about intentionality, capability and rationality to female patients where the very testing invokes gendered tropes. This in turn informs gendered social identities of both doctors and Pap smear patients, based on foregrounding the agency of doctors (the higher status actor in the doctor-patient dyad) and assuming gendered patient passivity - which, as detailed below, informs and is reinforced by the legislation surrounding cervical cancer screening in Australia.

Record-keeping technologies can have wider social ramifications as methods of surveillance. As Timmermans and Berg assert, 'medical technology is inevitably politics by other means'. ${ }^{50}$ As Foucault has intimated, medical and state surveillance may act as a Panopticonic method of disciplinary power. ${ }^{51}$ That power is internalised by the inmate of the medical Panopticon so that they comply with rules and expectations in the assumption that non-compliance will be observed and disciplined. ${ }^{52}$ In this 'subtle calculated technology of subjection' ${ }^{53}$ the 'cruel ingenious cage ${ }^{54}$ is the knowledge that one is observed, which encourages and requires one to either comply with rules or to face discipline if one revolts. It not only enforces compliance with medical norms by both patients and doctors, ${ }^{55}$ requiring compliance with externally imposed measures rather than negotiated and consensual preferences, but also reinforces external and internal power and gender roles by requiring each participant to play out their required role without demur.

Timmermans and Berg (2003), p 105.

Timmermans and Berg (2003), p 108.

Timmermans and Berg (2003), p 107.

Foucault (1975), eg p 592.

Foucault (1975), p 594.

Foucault (1975), p 598.

Foucault (1975), p 594.

Foucault (1975), p 593, where Foucault points out that the observer in the Panopticon hospital observes not only the patients, but also the doctors who tend them, to enforce the supervisors' orders upon their subordinates. 
Screening itself is part of fundamental epistemological shift in the meaning of medicine, health and the role of participants in the medical process. ${ }^{56}$ David Armstrong considers that the temporal and spatial locus of medicine has shifted from the hospital or clinic to a system of surveillance medicine, under which the focus of medicine becomes not the lesion treated by the clinic, signified by sign and symptom, but the management of risk factors over wide temporal spans. ${ }^{57}$ The role of the doctor in surveillance medicine shifts from responding to symptoms raised by a patient to exhorting patients to manage risks. ${ }^{58}$ Doctors, medicine and patients now focus to a much greater degree on 'the semi-pathological, pre-illness at-risk state' ${ }^{59}$ In this medical paradigm, to be well is only to be as yet unaffected by potential risk factors, which must be constantly managed: 'Medicine turns increasingly to an extracorporeal space - often represented by the notion of 'lifestyle' - to identify the precursors of future illness. ${ }^{60}$ Medicine then locates power in the doctor, who exerts that power over patients for whom wellness is pathologised into a pre-illness risk state. Patients are expected to assume responsibility for controlling both personal and population risk, in part by submitting to surveillance and control, including population screening for the hidden precursors of illness. ${ }^{61}$ This is doubly so for women, who are already presumed in Western culture to have unruly, pathological bodies. ${ }^{62}$

The following sections will outline how the Public Health Act creates the structures that will be contrasted with non-gender-specific care and then analysed in the light of gender binaries, which in turn will highlight the role of the Pap Smear Register as a gendered technology.

\section{Overview of the Legislative Framework for the Queensland Pap Smear Register}

In 1988, Australian state and federal governments created the Cervical Cancer Screening Evaluation Steering Committee, which recommended programs that eventually became the National Cervical Screening Program. ${ }^{63}$ The screening program follows the classic pattern for a screening system: 'the purposeful application of tests to an asymptomatic population in order to classify people into those who are unlikely to have or develop a disease and those who are likely to have or develop a disease ${ }^{94}$ in a way that will be

\footnotetext{
Armstrong and Eborall (2012), p 5; Armstrong (1995), p 395.

Armstrong (1995), p 402.

Armstrong (2012), p 189.

Armstrong (1995), p 401.

Armstrong (1995), p 401.

Armstrong (2012), p 189.

King (2013), p 31.

$63 \mathrm{http} / / /$ www.cancerscreening.gov.au/internet/screening/publishing.nsf/Content/cervicalabout. 
cost-effective or at least 'economically balanced' in relation to possible total medical care expenditure related to the risk identified, ${ }^{65}$ to allow those individuals to reduce their risk of disease, undergo further diagnostic testing or be treated for their condition. ${ }^{66}$

As part of the program, in 1999 Queensland established a Pap Smear Register. ${ }^{67}$ The current Queensland legislation regulating the Pap Smear Register is the Public Health Act 2005 (Qld). Part 3 of that act governs the Queensland Pap Smear Register. ${ }^{68}$ All Australian states have legislation that sets up similar Pap smear or cervical cytology registers, as part of the Australian National Cervical Screening Program - although not all of it is as detailed as the Queensland legislation. ${ }^{69}$ This article analyses the Queensland legislation because it is one of the most explicit legislative implementations of the Australian National Cervical Screening Program and demonstrates Australia's gendered approach to health care rights surrounding Pap smear registration and testing.

The legislation requires that the relevant departmental chief executive ${ }^{70}$ must maintain a Pap Smear Register that keeps information on the dates and results of a woman's Pap smear, histology and HPV tests, plus details of her name(s), birthdate and address. ${ }^{71}$ Pathology lab directors must provide those details to the chief executive, unless the request for pathology testing of the woman's Pap smear, histological sample or HPV test sample includes a notation that the woman's information must not be given to the chief executive. ${ }^{72}$

Armstrong and Eborall (2012), p 3.

Armstrong and Eborall (2012), p 2.

Health and Other Legislation Amendment Act 1998 (Qld), s 11, amending the Health Act 1937 (Q1d)

Public Health Act 2005 (Qld), s 253.

Public Health Act 2010 (NSW), Part 6 Division 2 and 3; Cancer Act 1958 (Vic), Part III. (This is drafted in generic and gender-neutral terms which could apply to all cancer registers, but is used to create the Victorian Cervical Cytology Register.) Public Health Act 1997 (Tas), Part 7 Division 1; Public Health Regulation 2000 (ACT), Part III; South Australian Public Health (Cervical and Related Cancer Screening) Regulations 2012 (SA); Public Health (Cervical Cytology Register) Regulations (NT). (The only cytology register legislation that refers to information being recorded with a woman's consent.) Health (Cervical Cytology Register) Regulations 1991 (WA). Though this legislation creates registers for Pap smear or cervical cytology results, not all of it is cognate to the Queensland legislation. However, all registers either require opting out for women who do not wish to participate or alternately have no option to remove oneself from the relevant register. The relevant Northern Territory regulation refers to information being recorded with the patient's consent, but also only gives a mechanism for the patient to refuse consent, not to give it. National screening recommendations inform how legislation will be applied and bring the application closer to the Queensland model.

Acts Interpretation Act 1954 (Qld), s 33.

Public Health Act 2005 (Qld), s 253.

Public Health Act 2005 (Q1d), s 259. 


\section{Entry on to the Pap Smear Register}

'Clinical and identifying information about a woman is to be included in the register unless the woman elects for it not to be included. ${ }^{, 73}$ The default position is that every woman who undergoes cervical cancer testing will have her information recorded in the Pap Smear Register.

Women may opt out of inclusion on the Pap Smear Register. The 'initial duty' of a Pap smear provider is that they must be 'satisfied, on reasonable grounds' that the woman has been informed of the existence and purpose of the register, the information about the woman which may be recorded on the register and that the woman may elect not to be automatically included on the register. ${ }^{74}$ The Act does not require the Pap smear provider to actually provide that information, only to be satisfied that the woman 'has been informed', which could include being satisfied that she has previously or elsewhere been informed. If the chief executive receives information about a woman for the first time, they must send a notice to the woman stating that her information has been included on the register, that she may have it removed or changed, and how she may do so. ${ }^{75}$ (There is no legislative requirement to confirm that the woman received information about the register.) Pap smear providers may know that the chief executive's notice is required, and may assume that if there is no recording of any optout on their records, a woman will be aware of the register if she has previously had a Pap smear. There is no legislative penalty for a medical practitioner failing to inform the patient about the Pap Smear Register, the use of information or that the patient can opt out.

The first time the patient tells the provider that she wants to opt out of the register, the Pap smear provider must make a note about her decision and that the woman's information must not be given to the chief executive. ${ }^{76}$ They must also include a notation on the woman's Pap smear, histology or HPV test requesting that the information must not be given to the chief executive. If there is such a notation, the relevant pathology lab must not give information about the woman to the chief executive. Again, there is no penalty for breach of any of these requirements.

If a woman has opted out of inclusion in the register, and a note of that decision appears in a Pap smear provider's notes, 'the provider must ask the woman whether she wishes to reconsider her decision' at each subsequent Pap smear visit. ${ }^{77}$ If the woman changes her mind, the provider must note that decision in their records that the woman's information must be given to the chief executive. ${ }^{78}$ If the woman continues to opt out, there is no requirement for an

Public Health Act 2005 (Qld), s 255.

Public Health Act 2005 (Qld), s 256.

Public Health Act 2005 (Qld), s 260.

Public Health Act 2005 (Qld), s 257.

Public Health Act 2005 (Qld), s 258(2).

Public Health Act 2005 (Qld), s 258(3). 
additional note in the provider's records. The only requirement is that they must place a notation on relevant pathology requests. ${ }^{79}$

A woman may also write to the chief executive to request removal of her screening history from the Pap Smear Register. ${ }^{80}$ This presumes that the woman will become aware of the existence of the Register, be aware that the Register contains her screening history, understand how information on the Register may be used and know that she may request removal of her information from the Register.

A Pap smear provider's duty to inform a patient about the Register is minimal. The provider does not need to provide information on each Pap smear visit. The provider does not have to receive specific instructions about consent for inclusion, as no consent is required. Whatever the woman's actual preference or state of knowledge, her failure to demure is sufficient for her private medical records to be included in the register. However, the provider must ask a woman to reconsider a prior decision to opt out at every subsequent Pap smear and does not have to record ongoing refusals to participate in the woman's health records. No ongoing consent is required.

\section{How Will Information on the Pap Smear Register be Used?}

Key objectives for the original establishment of the Queensland Pap Smear Register included to 'help in formulating strategies to encourage women to participate in cervical screening' and 'assisting individual women by providing a back-up reminder service'. ${ }^{81}$ To encourage women to attend regular cervical screening checks, the chief executive sends biennial screening reminders to women who have previously undergone cervical screening procedures. ${ }^{82}$ The presumption is that women are more likely to undergo regular screening if reminded and/or that women need reminders to remain in the Cervical Screening program.

Other key objectives are to 'provide accurate and comprehensive screening histories to health practitioners involved in the woman's clinical management and to pathology laboratories interpreting a woman's smear and making clinical management recommendations' and 'ensuring that woman are aware of recommended follow up action if a cervical abnormality is detected'. ${ }^{83}$ The chief executive may give medical practitioners reminders about the timing of a woman's cervical screening tests ${ }^{84}$ or access to a woman's screening history (but not address) if the chief executive is 'satisfied on reasonable grounds' that woman is a patient of the practitioner and the information will assist the practitioner to make reasonable diagnosis or

Public Health Act 2005 (Qld), s 257(3).

Public Health Act 2005 (Qld), s 263.

Quotes from the Health and Other Legislation Amendment Bill 1998 Explanatory Note, $\mathrm{p} 2$.

Public Health Act 2005 (Qld), s 261.

Health and Other Legislation Amendment Bill 1998 Explanatory Note, p 2 and Public Health Act 2005 (Qld), s 262.

Public Health Act (2005) (Qld), s 252. 
decisions about a woman. ${ }^{85}$ The chief executive may also give a woman's screening history to a pathology lab which is interpreting a woman's cervical screening samples or may wish to use the information for quality assurance. ${ }^{86}$

Researchers use information on the register for research, including epidemiological and statistical research into cervical cancer and screening efficacy. ${ }^{87}$ While normally a patient would specifically consent to their inclusion in research (other than large epidemiological studies) ${ }^{88}$ researchers do not need consent from Pap smear patients. Instead, they seek consent from the chief executive to use the register. ${ }^{89}$ Where a woman does not opt out of the Register, her rights are abrogated in a way that does not apply to most other health care situations.

\section{Gender and the Pap Smear Register}

\section{Differing Approaches for Differing Diseases}

Cervical cancer is a serious illness. However, it is not in the top ten causes of mortality for Australian women. ${ }^{90}$ There are screening tests for risk factors or presence of most of the top 10 causes of death. ${ }^{91}$ However, there are no government registers relating to mere testing for the top 10 causes of death in Australia. There are cancer registers, which record positive cancer diagnoses but not negative testing. ${ }^{92}$ The only testing-procedure registers are the opt-off cervical cytology testing register, a mixed invitation-based optoff/opt-in approach for bowel cancer screening and a primarily opt-off approach to mammogram screening. ${ }^{93}$ There is a differential standard for Pap smear and cervical cytology testing that does not apply to most other cancers or to more frequent causes of mortality in Australia.

\section{Don't Worry your Pretty Little Head: Reminders and Record Keeping for Medical Services}

One key component of the Australian National Cervical Screening program is that women receive biennial reminders to undergo screening. ${ }^{94}$ Studies

\footnotetext{
$85 \quad$ Public Health Act (2005) (Qld), s 272.

$86 \quad$ Public Health Act 2005 (Qld), s 273.

Public Health Act 2005 (Qld), Ch 6, Pt 4.

Takach (1995), p 66.

Public Health Act 2005 (Qld), s 282.

90 Ischaemic heart disease, stroke, dementia/Alzheimer's disease, trachea/lung cancer, chronic lower respiratory diseases, diabetes, colon/rectum cancer, blood/lymph cancer, kidney urinary system diseases, heart failure, according to http://www.abs.gov.au/ausstats/abs@.nsf/Lookup/by\%20Subject/1301.0 2012 Main\%20 Features Mortality,\%20life\%20expectancy\%20and\%20causes\%20of\%20death 231.

91 Royal Australian College of General Practitioners 'Red Book' Task Force (2009), pp 22-56. For example, the Queensland Cancer Register, Public Health Act 2005 (Qld), s 234.

93 Australian Government Department of Health.

See http://www.cancerscreening.gov.au/internet/screening/publishing.nsf/Content/cervicalabout, and Public Health Act 2005 (Qld), ss 261-262.
} 
have found that women are more likely to participate in regular preventative medical checks than men, ${ }^{95}$ and that screening is likely to be a greater focus of their medical care than for men, especially if the woman has a male doctor. ${ }^{96}$ Despite this, women are subject to legislated medical and government checking and reminders for cervical cancer screening. Why are women presumed to want or need such reminders of medical care?

Historically, Western conceptions of autonomy and rationality arise from negating the body to prioritise the rationality of mind. ${ }^{97}$ Women, as the binary opposite of men, were 'dependent, emotional, natural, passive female[s]', ${ }^{98}$ and were identified with the body rather than rationality of mind. The Pap smear test reinforces the patient's gender by directly involving genitalia, as well as assigning her a role of passivity. If a woman is conceived as the object of medical testing, with the doctor and pathologist as the active subjects of the process, if she is presumed passive and done-to rather than a doer, it is easy to see her as too passive to seek regular testing on her own initiative. It also firmly positions her in the gendered binary of mind/body, rationality/irrationality as being of the body and therefore irrational.

In this duality, man - the subject of law and autonomous public life, imbued with conscious rationality - would seek information and medical care as needed. This male subject seeks the medical contract and relationship with a similarly rational doctor. Woman, flighty and irrational, would be presumed to neglect her health care, because seeking appropriate health information is an act of intelligence and rationality. Even if she could be assumed to understand the value of health care, a woman would be presumed not to plan ahead and organise regular health interventions. If she could overcome her irrationality to understand the need for health care and appropriate intervals for care, woman's impassivity and lack of autonomy would presumably preclude her from scheduling appropriate appointments and seeking follow-up information. Therefore it would be appropriate for rational actors (doctors and/or the state) to send reminders to assist the woman to overcome her irrationality and passivity.

This is particularly so, if the health care is woman-specific. Men are presumed to make rational health-care decisions. It may even be considered patronising or insulting to remind a man that he needs health screening. Male doctors, in particular, are likely to focus on autonomous self-care primarily with men, but focus on doctor-based screening in discussions with women. ${ }^{99}$ However, where few men ${ }^{100}$ would need the particular test - and none of them cis-gendered men - irrationality is ascribed to the users of the test. The law

See, for example, the review of several studies in Pinkhasov et al (2010) .

Sandhu et al (2009), p 351.

Bray and Colbrook (1998), p 36.

Naffine (1995), p 24; as Naffine notes, this concept goes back to Aristotle.

Sandhu et al (2009).

The Act ignores that trans men or intersex individuals who identify as men may have cervixes or need health care stereotypically gendered as 'female' care. 
steps in, as it does in abortion or other 'women's' health care or social issues, to rationalise and 'responsibilise' the object of the testing and ensure that she participates in the testing scheme at the state's preferred screening intervals. Women are not treated as responsible, independent contractors for health care, as that is inconsistent with a passive, feminine role.

Therefore, the state, informed by the rationality of medicine and science, assumed that it must remind (irrational) women to attend cervical screening. The Public Health Act 2005 (Qld) largely concentrates on the powers and duties of rational actors who are its legal subjects (doctors, pathology directors and the chief executive of the relevant department) rather than the women who are the objects of their testing and record keeping. While this clearly reflects the centring of doctors in the Surveillance Medicine paradigm as those who detect asymptomatic risks, ${ }^{101}$ it goes much further than most social practices of Surveillance Medicine. The Act elides women as active seekers of health care and makes them again the objects of law and action by others. As passive objects, consuming but not seeking care, the woman of the Public Health Act's Pap smear screening regime sit and wait for reminders. She is not the Surveillance Medicine paradigmatic patient expected to internalise responsibility for avoiding risk, ${ }^{102}$ but is rather the passive recipient of state medical management. The Act thus is clearly influenced by and then reinforces gendered stereotypes of women as passive, childish, unintelligent and irrational, requiring external reminders for health care from more rational authority figures.

\section{But She Didn't Say No: Standards for Informing Patients, Consent and Use of Confidential Information}

The release of medical information under the cervical screening regime is problematic for several reasons. There is no requirement that a woman should consent to the release of her information. She does not have to confirm that a particular practitioner is treating her before her cervical cancer screening information may be released to the practitioner. A former treating practitioner with whom the woman has a dispute may have sufficient information to claim that the woman is their patient. So might a practitioner in a relationship with a woman. A new practitioner may gain access to a woman's prior records without her knowledge and permission - something that would normally not occur directly between medical practitioners. Practitioners may receive reminders or other information after a woman has ceased to be their patient.

Consent theory is at the basis of modern liberal political and social theory. ${ }^{103}$ Rational actors are assumed to be autonomous and inviolate. In liberal theory, any interference with the liberal subject's body or rights is presumed to require their consent. Medical treatment without consent is a trespass. ${ }^{104}$

\footnotetext{
$101 \quad$ Armstrong (1995), p 402.

$102 \quad$ Armstrong (1995), p 399.

103 Pateman (1980), p 151.

$104 \quad R v$ Donovan [1934] 2 KB 488.
} 
Doctors have a duty to provide sufficient information to patients to allow them to make informed consent to treatment and to any sharing of the patient's medical records. ${ }^{105}$ This is considered a 'prima facie' duty, which is linked directly to principles of patient autonomy ${ }^{106}$ and respect for the patient. ${ }^{107}$ This respect for autonomy is supposed to extend to the use of information and samples for research. ${ }^{108}$ In research, as Petrini explains:

In 'opt-in' systems, subjects incapable of expressing consent are generally excluded unless a legal representative provides valid consent. 'Opt-out' systems, on the other hand, are more ethically problematic, because they assume the subject understands the information, freely chooses and takes action if he does not want to participate. ${ }^{109}$

Patients expect to give informed consent to medical care and use of their records. US studies found that 'Ninety-one percent of people report that they are "very concerned" about the privacy and security of their personal health information', ${ }^{110}$ and in an early study, '78\% of respondents felt it is very important that medical records be kept confidential'. ${ }^{111}$ However, the Public Health Act 2005 (Qld) reverses normal patient preferences for and presumptions of confidentiality, to require that doctors register cervical screening records without seeking specific patient consent, unless the patient opts out of disclosure. ${ }^{112}$ That information may then be used for research, to issue reminders and to inform medical professionals, without the patient's specific consent. ${ }^{113}$

What level of information must doctors give to patients about confidentiality and disclosure of information under the Public Health Act 2005 (Qld)? As mentioned above, the Act only requires medical practitioners to be 'satisfied' that a woman is aware of the register and her ability to opt out. They are not legislatively required to provide information to the woman, or to check that the woman understands her options. The ability for women to opt out is also not highlighted to doctors on the National Cervical Cancer Screening website, where there is no information about the need to inform patients about opting out under 'Information for Health Professionals'. ${ }^{114}$

On the same site, there is very little information about opting out of Pap smear registers for cervical screening patients. The site gives no

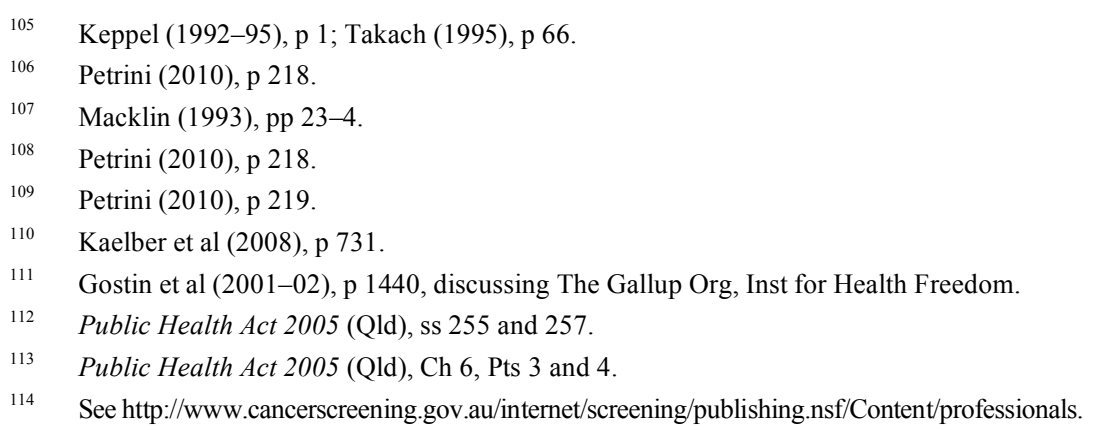


comprehensive statements about exactly what information is gathered and to whom it may be disclosed. ${ }^{115}$ There is also no clear statement informing patients how they may opt out. ${ }^{116}$ Such a statement would be very simple, as patients may opt out simply by informing their doctor. ${ }^{17}$

The standard Pap smear brochure available from the same national screening body explains how to opt out; it fails to explain how widely information on the register may be disseminated; merely implying the register is a reminder system. ${ }^{118}$ The standard brochure designed for Aboriginal and Torres Strait Islander women does not specifically alert them to any potential disclosures. ${ }^{119}$ It indicates only that information will be used to assist health-care providers and to send reminders. ${ }^{120}$ In fact, the register is described as 'confidential'. ${ }^{121}$

The woman provided only with these brochures is far from fully informed in her decision to opt out or stay silent. This clearly violates the principle that under an opt-out system, 'the subject understands the information, freely chooses and takes action if he [sic] does not want to participate. ${ }^{122}$

Doctors are generally split on the level of disclosure ethically necessary for informed consent, from those who would tell everything to those who believe patients should be told very little. ${ }^{123}$ Informed by the idea that the best interests of the patient are their primary consideration, ${ }^{124}$ most doctors agree that 'the extent of the warning is a matter for medical judgment with especial importance attached to the doctor's assessment of his patient'. ${ }^{125}$ Doctors consider that patients should be told enough to make what the doctor considers a beneficial decision, having regard to the capabilities of the patient, rather than being given all information. Patients perceived by doctors as better educated, more intelligent and more rational will usually be given more information and trusted to weigh more factors in making a decision. Doctors will give less information to patients who the doctor perceives as less intelligent or more passive. ${ }^{126}$ Because doctors have a duty to avoid harming their patients, patients who are perceived as being overly emotional or easily worried may not be provided with distressing information. ${ }^{127}$

See http://www.cancerscreening.gov.au/internet/screening/publishing.nsf/Content/register.

116 See http://www.cancerscreening.gov.au/internet/screening/publishing.nsf/Content/register.

117 For example, in Public Health Act 2005 (Qld), s255.

118 National Cervical Screening Program (2012).

119 Healthy Women's Initiative (2012).

120 Healthy Women's Initiative (2012).

121 Healthy Women's Initiative (2012).

122 Petrini (2010), p 219.

123 Scutt (1997), p 295.

124 Scutt (1997), p 295.

125 Sidaway v. Board of Governors of the Bethlem Royal Hospital Governors [1985] AC 871.

126 Scutt (1997), p 300.

127 For example, despite deaths in the cohort, women exposed to fertility drugs based on human pituitary growth (hPG) hormone potentially contaminated with Creutzfeld-Jacob
} 
If women in a gender dichotomy are subconsciously presumed to be generally unintelligent, irrational, irresponsible, emotional and passive, ${ }^{128}$ doctors are likely to perceive women as needing to be protected from detailed information and needing guidance to take the doctor's preferred treatment. Thus they are less likely to give detailed information about Pap smear registers to women, and more likely to stress benefits like biennial reminders while glossing over consent and privacy issues.

Compounding medical perceptions of women's otherness and the irrelevance of proper consent by women is the very nature of the Pap smear test and women's gynaecological realities. As Bridgeman says, 'Within the particular symbolic system known as patriarchy, the only possible subjectposition is masculine, the only feminine identity available to women is that of "defective" or "castrated" men'. ${ }^{129}$ As Bray and Colbrook explain, 'women's bodies are positioned as prerepresentational, silent, negated, and violently objectified by an active male reason'. ${ }^{130}$ In discussing Naffine's work, Savell expands upon this to state:

Naffine argues that law's principal concern 'is (the policing of the
boundaries of the bounded heterosexual male body. Bodies which are
not like this or are not allowed to be like this, are somehow deviant
and undeserving bodies. They are 'unnatural', even 'loathsome'
because they have apparently lost their clear definition.' This
produces what Naffine describes as the 'logic of a bounded self.'
Within this logic, bodies that appear to lack definition appear to be
'unbounded'. Furthermore, because bodily boundary is an essential
pre-requisite to dignity, the 'unbounded' subject is reduced in
status.

Pap smears underline this unbounded state, highlighting vaginas, cervixes and uteri, the sources of women's menstruating, pregnancy-bearing nonbounded reality. Where the right to information and consent is based in patient dignity and autonomy, possessing an unbounded body, ideologically constructed as a body without dignity, automatically positions a woman as less deserving of information, less able to rationally consent to use of her records and more able to be violated, as violation matters most where boundaries are presumed to be inviolable.

disease were less likely to be warned and suffered a longer delay in warnings than a mixed-gender group treated with different drugs based on the same potentially contaminated hPG as children. Part of the reasoning was 'it was decided that it was not in the recipients' interest to tell them unnecessarily - there was nothing to be gained from worrying them'. Scutt (1997), pp 304-6.

128 Naffine (1995), p 25.

129 Bridgeman (1993), p 3.

$130 \quad$ Bray and Colbrook (1998), p 36.

131 Savell (2001), pp 438-9, quoting Naffine (1998), p 84. 
Pap smears involve penetration by medical instruments, seen by judges and doctors as an intrusion and violation of (men's) inviolable boundaries. ${ }^{132}$ By undergoing experiences uniquely identified with uteri-possession, patients 'relinquish their subjectivity and revert to their traditional status as man's other'. ${ }^{133}$ Woman, penetrated with a speculum, is cast as both a medical object and sex object, with her status accordingly reduced. ${ }^{134}$ By allowing herself to be penetrated, she has demonstrated that her rights, her autonomy may be violated, compared with the bounded body of a rational man, who in heteronormative ideology is not subject to penetration.

Women themselves internalise their objectification. ${ }^{135}$ Pateman posits that, 'Objectification makes sexuality a material reality of women's lives, not just a psychological, attitudinal or ideological one ... made to appear a quality of the object itself. ${ }^{136}$ Thus woman is for sex, for doing-to, not a rational actor, but an object to be penetrated. If she is for penetration then her consent is presumed, obliged or unnecessary. In rape culture, that plays out as being assumed to submit to sexual approaches and acts, unless a woman specifically refuses and perhaps not even then. ${ }^{137}$ As Pateman comments, 'Apparently refusal of consent can never, in a woman, be taken at face value', ${ }^{138}$ necessitating enquiring in rape cases whether 'no' means 'yes'. ${ }^{139}$

Penetration is the subjective heteronormative sex act of normative male bodies. Thus the doctor - male or female - reiterates their subject position as not only the rational medical professional, but the active, subject penetrator of the object women. The status of patients as Pap smear objects and sexual objects results in a presumed state of consent to penetration during the Pap smear.

This object position is mirrored in the level of consent required for the woman's participation in the Pap Smear Register. She is the sexualised object assumed to consent to use unless she specifically and clearly negatives each act of entry on to the Register. Once she fails to clearly object, she is assumed to consent and to continue to consent to participate in the Register without being consulted. However, her refusal must be irrational and questioned at every visit. ${ }^{140}$ Further, the woman's body is the object of the medical transaction, her medical information the resource of her doctor and medical researchers, not her own. The Public Health Act dispenses with

132 For example, in Bland, where it was assumed that the vegetative Mr Bland would have preferred death to an existence which required him to live only if constantly penetrated by feeding tubes and other medical equipment. Airedale Hospital Trustees v Bland [1993] 1 All ER 821.

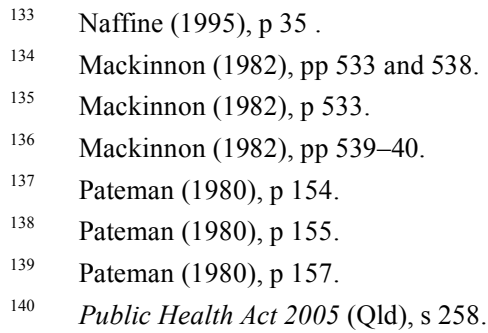


woman's consent because it is based in rape culture norms about the unimportance of women's consent and autonomy. It further reinforces the trope that consent to one act characterised as sexual, because a vagina is penetrated (even though a Pap smear is far from sexual for most women), means a woman's consent is unnecessary for any further violation of her autonomy. The Public Health Act reinforces this presumption that consent to penetration reduces women's rights to privacy, boundaries and dignity.

\section{But Think of the Children! Women's Obligations to Family, Society and Medical Research}

Even if women are fully informed of the use of Pap smear register information, they are likely to feel pressure to participate. Gender expression is a learned quality, ${ }^{141}$ in which "woman" [is] a social construction ... made for child care, home care and husband care'. ${ }^{142}$ Both nurturing of others and child-bearing are constructed as essential parts of acting as a woman. ${ }^{143}$ Women's sphere and interests are often treated by theorists as synonymous with 'the family'. ${ }^{144}$ Women who resist such role ascriptions are socially perceived as defective women. ${ }^{145}$

Women are identified with the private/family sphere, while men - as liberal subjects - are more often identified with public spaces. As women have moved into public space, they have experienced demands for payment for participation in the public space in the form of reduction of rights. ${ }^{146}$ 'Something that accompanies the rules that dictate how a woman can take up space is the commoditisation of her body in order to "pay" for that space. ${ }^{147}$ In the realm of cancer screening, women experience the demand that they automatically consent to invasion of their privacy for participation in the benefits of public screening.

Women conditioned to those values may also internalise responsibilities to put aside their boundaries, privacy and autonomy to take part in research to benefit other women and reduce the social costs of cancer treatment and research. Social pressures and conditioning may influence the freedom of consent. ${ }^{148}$ Women may submit to expectations that they owe society their fertility, and must put aside their own preferences in order to nurture social goods by undergoing screening that preserves the social resource of female fertility.

Failure to comply with pressures to sacrifice for society, in a way not expected of men, leads to women again being characterised as irrational,

\footnotetext{
$141 \quad$ Mackinnon (1982), p 529.

142 Mackinnon (1982), p 530.

143 Crenshaw (1996), p 173.

144 Mackinnon (1982), p 525.

145 Mackinnon (1982), p 530.

146 Audley-Coote (2012).

147 Audley-Coote (2012).

148 Mackinnon (1982), p 530.
} 
where it would be rational for a man to prioritise autonomy. The explanatory memorandum to the Bill that introduced the Pap Smear Register to Queensland exemplifies this when it states:

\begin{abstract}
Experience from other jurisdictions (ie New Zealand and New South Wales) was that poor participation rates resulted when women were required to actively choose to participate in the Register before their information was included. Poor participation rates had significant adverse effects upon the fulfilment of the identified public health policy objectives. The evidence from these jurisdictions is that the low participation rate could not be attributed to significant levels of conscientious objection to participation in the Register, but rather due to the absence of proactive efforts by women to have themselves included in the Register. ${ }^{149}$
\end{abstract}

Where, for a man, respect for privacy and autonomy was the prima facie position in medical processes, woman were expected to make 'proactive efforts' to include themselves in registers to benefit public health objectives. Unless preferences for privacy reach the level of clearly articulated 'conscientious objection' (strong 'rational', religious or philosophically based objections), women's reasons for not becoming the subject of research were invalidated, where an obvious explanation, a preference for privacy of medical information would be expected and respected for men.

Women, as the object of medical and male gaze, were acting irrationally and against expected gender roles if they did not open medical records to the state's gaze, and did not put the interests of others (public health) ahead of their own interest in medical privacy. Therefore, their preference was counter-stereotypical, which made it irrational and meant it should be ignored. Thus their consent could be dispensed with and they should be forced to be the subject of research and exposure, as that would be the role they would take if they were 'proper' women. Despite such clear evidence that many women did not choose to participate in privacy violations, the legislation reinforces this conception that women's privacy and consent are unimportant. It enforces gender roles by dispensing with consent to information-sharing. It legislatively compels exposure to medical, research and state surveillance.

\title{
Doctor Knows Best
}

As women internalise othered identities, they and their doctors simultaneously internalise tropes about health care providers. Our society places enormous value on good health and normative bodies. ${ }^{150}$ Because of that, as Maclean says, medical professionals as 'guardians of that health have enormous power and their status as scientists reinforces their position

\footnotetext{
149 Health and Other Legislation Amendment Bill 1998, Explanatory Note, p 2.

$150 \quad$ Maclean (1999), p 9.
} 
in the new meritocracy'. ${ }^{151}$ Haraway considers that, as a result, 'We have granted science the role of a fetish, an object human beings make only to forget their role in creating it. ${ }^{152}$

Unfortunately, 'objectivity is the methodological stance of which objectification is the social process'. ${ }^{153}$ Scientists and doctors become the active subject while women become the object upon which they act. ${ }^{154}$ The rights of patients are disregarded, while the needs of researchers are elevated, their claimed objectivity, scientific reasoning and situated subjectivity trumping women's interests to resituate women as medical objects. ${ }^{155}$ As the ultimate arbiter of rational decisions, science decides who will 'benefit from its capacities or be subject to its experiments'. ${ }^{156}$ After all, if the scientist is rational, dispassionate, intelligent and objective, a woman who disagrees with science's demands is automatically perceived as irrational, stupid and selfish. Any objection to inclusion in research is therefore presumed to be irrational, stupid and selfish, and may be disregarded by more rational actors. Women may easily be relegated to the 'category of guineapig'. ${ }^{157}$ The Public Health Act both reflects this scientific role relegation and reinforces it in the mind of researchers who seek access to women's records without women's consent.

Research and science also create their own representations of reality, including representations of scientific objects and actions - representations that Fujimura argues 'can and often do become reified and stripped of the context of their production ... once ideas or theories become resituated, they can be used like technologies and instruments in the production of further representations'. ${ }^{158}$ Once technologies and ideas become reified, they affect the framing of new ideas and critiques. ${ }^{159}$ The idea of epidemiological research from publicly collected records has been resituated as an essential tool for research, rather than a convenience for researchers, who would otherwise have to gather information from multiple sites (hospitals, etc) or multiple subjects (as they must for other medical tests). When a public register is situated as an essential public health tool, the questions become how to encourage participation, rather than whether the format of the register is unnecessarily intrusive or there are other effective methods to reach the same goals. The Public Health Act adopts this reification of public registers as a necessary research tool, even though other research options exist, such

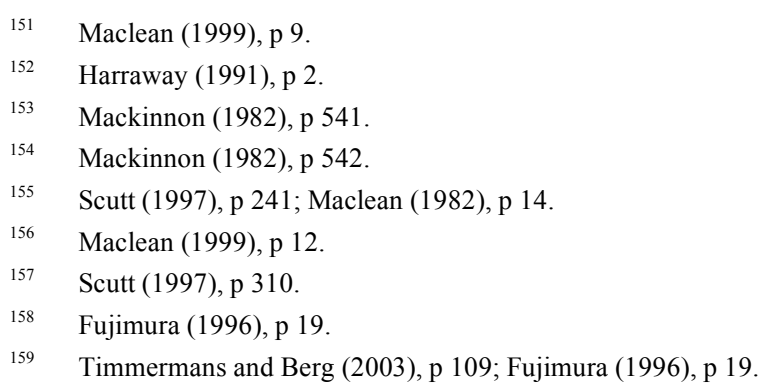


as using general cancer notification registers, rather than the unusual model of a register for mere tests.

\section{Surveillance}

Though cast as benefiting society and women, the Act also makes the job of doctors and researchers easier by siting power over cervical cancer screening and record-keeping with the state rather than with individual autonomous doctors and patients. The state submits to the presumption that medical technologies and methodologies are overriding interests, demonstrating Foucault's predictions of the rise of supra-legal disciplinary power based in scientific practices, which then simultaneously supplant and supplement the power of the state. ${ }^{160}$

Women who fail to consent to the power of science, medicine and researchers are constituted as obstructions rather than autonomous actors. The obstruction is removed by legislation, which is motivated by compliance with the supra-legal authority of medical researchers.

In addition to consent being waived for the interest of society and researchers, the placement of women on the Pap Smear Register is intended to achieve additional social goals in the reduction of cancer mortality and the rise of population-wide cancer screening. This is achieved via state surveillance of women using reminders and recording of compliance. Women, in turn, internalise the need for regular testing, internalising compliance with state and medical as they internalise compliance with femininity standards to please the male gaze. ${ }^{161}$ Women are acculturated to anticipate and comply with others' expectations - especially those of unquestioned authority figures like doctors. Under the gaze of this medical panopticon, they internalise the need for regular testing of all sorts, and the need to comply with medical recommendations. The internalised calendar for medical testing becomes an obligation to submit to testing and remain healthy.

The surveillance extends to the medical practitioners, who must comply with legislative testing regimes, times and processes, and registration regimes, in the knowledge that they are also subject to surveillance. They thus internalise the state's interests in registration and standardised care, whatever their patient's preferences or what newer research reveals.

This surveillance over testing is not present for any other health conditions apart from breast cancer and, in a limited form, colorectal cancer. It is not considered appropriate for most health conditions that significantly contribute to men's mortality. Thus, for men, privacy rather than compliance is considered the overriding virtue. The Act subjects women to surveillance and social discipline in a way that is largely absent from men's lives.

\footnotetext{
$160 \quad$ Foucault (1981), p 107.

161 Mackinnon (1982), pp 539-40, note 59.
} 


\section{It's for Your Own Good: Is the Pap Smear Register Approach Justified by its Benefits?}

The classic conditions for screening proposed by Wilson and Jungner in $1968,{ }^{162}$ and endorsed by the World Health Organization, are:

(a) The condition should be an important health problem.

(b) There should be an accepted treatment for patients with a recognised disease.

(c) Facilities for diagnosis and treatment should be available.

(d) There should be a recognisable latent or early symptomatic stage.

(e) There should be a suitable test or examination.

(f) The test should be acceptable to the population.

(g) The natural history of the condition, including development from latent to declared disease, should be adequately understood.

(h) There should be an agreed policy on whom to treat as patients.

(i) The cost of case finding (including diagnosis and treatment of patients diagnosed) should be economically balanced in relation to possible expenditure on medical care as a whole.

(j) Case-finding should be a continuing process and not a 'once and for all' project. ${ }^{163}$

Cervical cancer is a dangerous and deadly disease if not diagnosed and treated early. There is a clear, inexpensive process for finding a latent risk factor for the disease and clear patient group (people with cervixes), so it fits the criteria for public screening.

The Cervical Cancer Screening program, with its concomitant Pap Smear Register, has shown a reduction in cervical cancer rates since its inception. ${ }^{164}$ This reduction in cancer is linked in part with increases in cervical cytology services, leading to more women having high grade abnormalities detected and treated before they became cancerous. ${ }^{165}$ With systematic population screening, cervical cancer mortality rates have also dropped, from 3.9 deaths per 100,000 women in 1991 to 1.9 deaths per 100,000 women in 2007 (age adjusted) ${ }^{166}$ Mortality rates are clearly linked to early abnormality detection, but are also likely to be affected by increasingly effective treatment options and public awareness campaigns.

In Australia, in 2007-2008 86.3 per cent of eligible women undertake cervical cancer testing within each two- to five-year period. ${ }^{167}$ Only 208 women

\footnotetext{
162

Wilson and Jungner (2011).

163 As quoted in Armstrong and Eborall (2012), p 3.

164 A total of 715 new cases in Australia in 2006 compared with 1092 detected in 1991: http://www.health.gov.au/internet/screening/publishing.nsf/Content/facts.

165 In 2008, the National Cervical Screening Program detected 15,814 women in the target age group with high-grade abnormalities:

http://www.health.gov.au/internet/screening/publishing.nsf/Content/facts.
} 
died of cervical cancer. ${ }^{168}$ Does the Australian cervical screening system lead to a reduction in mortality compared to countries without similar register systems?

Comparative westernised societies have similar cervical cancer rates, whether or not they have similar registers. North American statistics show an incidence of 5.7 women per 100,000 diagnosed with cervical cancer in 2008 (compared with 5 per 100,000 in Australia/New Zealand) and mortality rates of 1.7 per 100,000 (compared with 1.4 per 100,000 in Australia/New Zealand in the same period) (all figures are age adjusted). Similarly, in Western Europe in 2008, cervical cancer incidence and mortality rates were also relatively low (incidence of 6.9 per 100,000 and mortality of 2 per 100,000 , age adjusted). ${ }^{169}$

Cervical screening data collection in the United Kingdom is publicly managed via the NHS, using an informed consent model for screening. ${ }^{170}$ Other European countries have a mix of approaches, including provision of information, advertising and reliance on private medical advice rather than public intervention, ${ }^{171}$ similar to the approaches to less gendered screening and health-risk management for other major diseases in Australia. ${ }^{172}$ In the United States and Europe, where cervical cancer incidence and mortality are generally low, there are screening programs, but the use of registers varies and is very frequently non-existent beyond general cancer registers. Differences of approach to registers has very little impact on cancer incidence and mortality in Western countries with cultures and public education programs similar to Australia, ${ }^{173}$ whereas the existence of population screening itself may reduce incidence and mortality rate by at least 80 per cent. ${ }^{174}$ Significantly higher cervical cancer rates occurred in different cultural millieux in Africa, South Asia, the Caribbean and South

168 See http://www.health.gov.au/internet/screening/publishing.nsf/Content/facts.

169 Arbyn et al (2011), p 2678; Jemal (2011), p 80.

170 Armstrong and Eborall (2012), p 6.

171 For United Kingdom, see http://www.cancerscreening.nhs.uk/cervical/whodoeswhat.html. For European approaches to screening, see Anttila et al (2004), p 936.

172 Royal Australian College of General Practitioners 'Red Book' Task Force (2009), pp 2256. There is no testing register regime for any of the top ten causes of death in Australia. Testing regimes for risk factors exist - for example, for cholesterol, etc - but they are not the subject of legislative schemes, though they do fit the criteria for public screening articulated by Wilson and Jungner (2011) and are recommended for regular private (nonlegislatively based) screening by the Royal Australian College of General Practitioners 'Red Book' Task Force, which publishes its Guidelines for Preventative Activities in General Practice as standards of good practice for all Australian GPs. An analysis of the etiology of disease processes and screening options for non-cervical cancer diseases is beyond the scope of this article, though Armstrong and Eborall (2012) discuss the sociology of screening extensively across many screening processes, and the Australian recommended screening options are discussed extensively in the Guidelines for Preventative Activities in General Practice Royal Australian College of General Practitioners 'Red Book' Task Force (2009).

173 Anttila et al (2004), p 938. Arbyn et al (2011), p 2682.

$174 \quad$ Anttila et al (2004), p 937. 
America, though this is likely due, at least in part, to significantly higher rates of HPV and HIV transmission, plus related co-factors such as smoking and oral contraceptive use. ${ }^{175}$

It is clear that successful population screening for cervical cancer in culturally westernised countries is not reliant on registers, state reminders or the types of gendered stereotyping underlying the Australian cervical cytology screening program. Low cervical cancer rates in westernised countries may be in part due to other cultural factors, as well as a range of screening approaches. There appears to be no efficacy justification for the particularly stereotyped and gendered approach adopted in the Public Health Act 2005 (Qld).

\section{Conclusion: Who is the Woman of the Public Health Act 2005(QId)?}

It is clear that the writers of the Queensland Pap Smear Register legislation were influenced by gendered presumptions about women, as well as by conceptions of science and medicine as rational and overriding interests. Even privileging of rationality itself is related to patriarchal norms and ideals. The writers mirror approaches to communication with women by many male doctors, who downplay the agency of women patients and emphasise screening rather than autonomous self-care. ${ }^{176}$

The Act clearly presupposes that women are irresponsible, in that they are unlikely to undertake simple life-saving screening tests without reminders. They are also considered to have poor memories, be of low intelligence, be duplicitous or be unable to communicate prior cervical screening activities, making it necessary for screening professionals to seek the information from a central register.

Further, women are required to put aside their interests in privacy and autonomy because of social presumptions about women as nurturing and sacrificing their own interests for researchers and society. Women's desire for agency, privacy and autonomy rights are considered less important, less rational, less gender-role appropriate and less vital than men's. Where women do not comply with role presumptions, the Act replicates rape society tropes about the (lack of) necessity for women's consent. The consent question in the act is 'Did she say no, clearly and every time?' rather than 'Did she say yes?'

As well as being influenced by dominant patriarchal tropes, the Act reinforces and replicates those tropes, repeating them back to women, health-care professionals and researchers. It reinforces that women cannot be trusted to give information or act rationally. It reinforces the active, dominant role of science and medicine, and that women are the object of that process, but that women do not get to decide the boundaries of their care and rights. By imposing no penalty for ignoring a 'no' (an opt-out), the Act reinforces the lack of importance accorded to women's autonomy and rights. 
None of this is necessary. Functional, successful cervical cancer screening can be run without a register that reinforces gender tropes. Women's health can and should be promoted without creating and reinforcing toxic gendered identities.

Research can be undertaken as it is for almost all other cancers, through general cancer registers, or approaches to patients and health providers, rather than through a system that reduces women's privacy and autonomy simply due to having routine health tests. The same research, screening and health goals could be met by non-gendered approaches that do not single women out for surveillance, as is demonstrated by effective North American and European approaches to population screening for cervical cancer.

\section{References}

\section{Secondary Sources}

A Anttila, G Ronco, G Clifford, F Bray, M Hakarma, M Arbyn and E Weiderpass (2004) 'Cervical Cancer Screening Programmes and Policies in 18 European Countries' 91 British Journal of Cancer 935.

M Arbyn, X Castellsague, S de Sanjose, L Bruni, M Saraiya, F Bray and J Ferlay (2011) 'Worldwide Burden of Cervical Cancer in 2008' 22 Annals of Oncology 2675.

Charlotte Audley-Coote (2012) 'Bodies: Taking Up Space', uqwomynews http://womynews.wordpress.com/2012/09/24/bodies-taking-up-space.

David Armstrong (1995) ‘The Rise of Surveillance Medicine’ 17 Sociology of Health \& Illness 393.

David Armstrong (2012) 'Screening: Mapping Medicine's Temporal Spaces' 34 Sociology of Health \& Illness 177.

Natalie Armstrong and Helen Eborall (2012) 'The Sociology of Medical Screening: Past, Present and Future' 34 Sociology of Health \& Illness 161.

Australian Institute of Health and Welfare (2010) Cancer in Australia: An Overview 2010, AIHW.

Australian Institute of Health and Welfare (2010) Cervical Screening in Australia 2007-2008: Data Report, AIHW.

Peter D Baade, Robert A Gardiner, Megan Ferguson, Danny R Youlden, Joanne F Aitken, John Yaxley and Suzanne K Chambers (2012) 'Factors Associated with Diagnostic and Treatment Intervals for Prostate Cancer in Queensland Australia' Cancer Causes Control 625.

Abigail Bray and Claire Colbrook (1998) 'The Haunted Flesh: Corporeal Feminism and the Politics of (Dis)embodiment' 24 Signs 35.

Jo Bridgeman (1995) ‘They Gag Women, Don't They?' in Jo Bridgeman and Susan Mollns, Law and Body Politics: Regulating the Female Body, Dartmouth.

Judith Butler (2004) Undoing Gender, Routledge.

Carrie Crenshaw (1996) 'The Normality of Man and Female Otherness: (Re)producing Patriarchal Lines of Argument in the Law and the News' 32 Argumentation and Advocacy 170.

Michel Foucault (1975) 'Panopticonism', republished in Robert C Scharff and Val Dusek (eds), Philosophy of Technology: The Technological Condition - an Anthology, Blackwell.

Michel Foucault (1981) 'Two Lectures', in Gordon Colin (ed), Power/Knowledge: Selected Interviews \& Other Writings by Michel Foucault 1972-1977, Pantheon.

Michel Foucault (1983) The Culture of the Self, Regent's Lecture, University of California, Berkeley. Joan H Fujimura (1996) Crafting Science: A Sociohistory of the Quest for the Genetics of Cancer, Harvard University Press. 
Lawrence O Gostin and James G Hodge (2001-02) 'Personal Privacy and Common Goods: A Framework for Balancing Under the National Health Information Privacy Rule' 86 Minnesota Law Review 1439.

B Green (2012) 'Applying Feminist Ethics of Care to Nursing Practice' 1 Journal of Nursing Care 1.

Donna J Haraway (1991) Simians, Cyborgs, and Women: The Reinvention of Nature, Free Association Books

Healthy Women's Initiative (2012) Why Should I Have a Pap Smear? Healthy Aboriginal and Torres Strait Islander Women in Mind, Body and Spirit, Queensland Government.

Judith A Howard (2000) 'Social Psychology of Identities' 26 Annual Review of Sociology 367.

Ahmedin Jemal, Freddie Bray, Melissa M Center, Jacques Ferlay, Elizabeth Ward and David Forman (2011) 'Global Cancer Statistics' CA: A Cancer Journal for Clinicians 69.

David C Kaelber, K Ashsish, Douglas Johnston, Blackford Middleton and David W Bates (2008) 'A Research Agenda for Personal Health Records (PHRs)' 15 Journal of the American Medical Informatics Association 629.

Gavin Kendall and Mike Michael (nd) 'Order and Disorder: Time, Technology and the Self' http://www.culturemachine.net/index.php/cm/article/viewArticle/242/223.

Susan Keppel (1992-95) 'Use of Personal Health Information by Third Parties for Research Purposes' 7 Auckland University Law Review 1.

Angela King (2013) 'The Prisoner of Gender: Foucault and the Disciplining of the Female Body' 5 Journal of International Women's Studies 29.

Catharine A Mackinnon (1982) 'Feminism, Marxism, Method and the State: An Agenda for Theory' 7 Feminist Theory 515.

Ruth Macklin (1993) 'Women's Health: An Ethical Perspective' 21 The Journal of Law, Medicine \& Ethics 23.

Maclean Sheila (1999) Old Law, New Medicine: Medical Ethics and Human Rights, Pandora.

Patricia Mahoney, Linda M Williams and Carolyn M West (2001) 'Violence Against Women by Intimate Relationship Partners', in Raquel Kennedy Bergen, Jeffrey L Edlieson and Clair M Renzetti (eds), Sourcebook on Violence Against Women, Sage.

Susan Mendus (1993) 'Different Voices, Still Lives: Problems in the Ethics of Care' 10 Journal of Applied Philosophy 17.

Ngaire Naffine (1995) 'Sexing the Subject (of Law)', in Thornton Margaret (ed), Public and Private: Feminist Legal Debates, Oxford University Press.

Ngaire Naffine (1998) 'The Body Bag', in Ngaire Naffine and Rosemary Owens (eds), Sexing the Subject of Law, Sweet and Maxwell.

National Cervical Screening Program (2012) When Did You Last Have a Pap Smear? NCSP.

Nigel Parton (2003) 'Rethinking Professional Practice: The Contributions of Social Constructionism and the Feminist "Ethics of Care" 33 British Journal of Social Work 1.

Carole Pateman (1980) 'Women and Consent' 8 Political Theory 149.

Carlo Petrini (2010) “"Broad" Consent, Exceptions to Consent and the Question of Using Biological Samples for Research Purposes Different from the Initial Collection Purpose' Social Science \& Medicine 217.

RM Pinkhasov, J Wong, J Kashanian, M Lee, DB Samadi, MM Pinkhason and R Shabsingh (2010) 'Are Men Shortchanged on Health? Perspective on Health Care Utilization and Health Risk Behaviour in Men and women in the United States' The international Journal of Clinical Practice 475.

Cecilia L Ridgeway (2009) 'Framed Before We Know It: How Gender Shapes Social Relations' 23 Gender \& Society 145. 
Royal Australian College of General Practitioners 'Red Book' Task Force (2009) Guidelines for Preventative Activities in General Practice, Royal College of General Practitioners

Harbinder Sandhu et al (2009) 'The impact of gender dyads on doctor-patient communication: A systematic review' 76 Patient Education and Counseling 348.

Kristine Savell (2001) 'Human Rights in the Age of Technology: Can Law Rein in the Medical Juggernaut?' 23 Sydney Law Review 423.

Jocelynne A Scutt (1997) The Incredible Woman: Power and Sexual Politics Volume 1, Artemis.

Selma Sevenhuijsen (2003) 'The Place of Care The Relevance of the Feminist Ethic of Care for Social Policy' 4 Feminist Theory 179.

Sally Sheldon (1993) “'Who is the Mother to Make the Judgment?"” The Constructions of Woman in English Abortion Law' 1 Feminist Legal Studies 3.

Ryan Takach (1995) 'No-(one's) Fault: The New Zealand Cervical Cancer Experiments' 3 Journal of Law and Medicine 60.

Stefan Timmermans and Marc Berg (2003) 'The Practice of Medical Technology' 25 Sociology of Health \& Illness 97.

Candace West and Don H Zimmerman (1987) 'Doing Gender' 1 Gender and Society 125.

JMG Wilson and G Jungner (2011) Principles and Practice of Screening for Disease. Geneva: World Health Organisation.

\section{Cases}

Airedale Hospital Trustees v Bland [1993] 1 All ER 821

$R v$ Donovan [1934] 2 KB 488

Sidaway v. Board of Governors of the Bethlem Royal Hospital Governors [1985] AC 871

\section{Legislation}

Acts Interpretation Act 1954 (Qld)

Cancer Act 1958 (Vic)

Health Act 1937 (Qld)

Health (Cervical Cytology Register) Regulations 1991 (WA

Health and Other Legislation Amendment Act 1998 (Qld)

Health and Other Legislation Amendment Bill 1998

Public Health (Cervical Cytology Register) Regulations (NT)

Public Health Act 1997 (Tas)

Public Health Act 2005 (Qld)

Public Health Act 2010 (NSW)

Public Health Regulation 2000 (ACT)

South Australian Public Health (Cervical and Related Cancer Screening) Regulations 2012 (SA) 